\title{
Hearing impairment in Stickler syndrome: a systematic review
}

\author{
Frederic R E Acke ${ }^{1 *}$, Ingeborg J M Dhooge ${ }^{1}$, Fransiska Malfait ${ }^{2}$ and Els M R De Leenheer ${ }^{1}$
}

\begin{abstract}
Background: Stickler syndrome is a connective tissue disorder characterized by ocular, skeletal, orofacial and auditory defects. It is caused by mutations in different collagen genes, namely COL2A1, COL11A1 and COL11A2 (autosomal dominant inheritance), and COL9A1 and COL9A2 (autosomal recessive inheritance). The auditory phenotype in Stickler syndrome is inconsistently reported. Therefore we performed a systematic review of the literature to give an up-to-date overview of hearing loss in Stickler syndrome, and correlated it with the genotype.

Methods: English-language literature was reviewed through searches of PubMed and Web of Science, in order to find relevant articles describing auditory features in Stickler patients, along with genotype. Prevalences of hearing loss are calculated and correlated with the different affected genes and type of mutation.

Results: 313 patients (102 families) individually described in 46 articles were included. Hearing loss was found in $62.9 \%$, mostly mild to moderate when reported. Hearing impairment was predominantly sensorineural (67.8\%). Conductive (14.1\%) and mixed (18.1\%) hearing loss was primarily found in young patients or patients with a palatal defect. Overall, mutations in COL11A1 (82.5\%) and COL11A2 (94.1\%) seem to be more frequently associated with hearing impairment than mutations in COL2A1 (52.2\%).

Conclusions: Hearing impairment in patients with Stickler syndrome is common. Sensorineural hearing loss predominates, but also conductive hearing loss, especially in children and patients with a palatal defect, may occur. The distinct disease-causing collagen genes are associated with a different prevalence of hearing impairment, but still large phenotypic variation exists. Regular auditory follow-up is strongly advised, particularly because many Stickler patients are visually impaired.
\end{abstract}

Keywords: Stickler syndrome, Arthro-ophthalmopathy, Collagen, COL2A1, Hearing loss, Cleft palate

\section{Introduction}

Stickler syndrome or hereditary progressive arthroophthalmopathy [1] (ORPHA828) is a connective tissue disorder affecting about $1 / 7,500$ to $1 / 9,000$ newborns [2]. It is characterized by ocular, skeletal, orofacial, and auditory abnormalities. Typical features include vitreoretinal degeneration, high-grade myopia, retinal detachment, premature osteoarthritis, midfacial hypoplasia, cleft palate and hearing loss [3,4].

Stickler syndrome is subdivided into several subtypes, based on its underlying genetic collagen defect. At present, defects in three different collagen genes have been found in patients with autosomal dominant Stickler

\footnotetext{
* Correspondence: frederic.acke@ugent.be

'Department of Otorhinolaryngology, 1P1, Ghent University / Ghent

University Hospital, De Pintelaan 185, Ghent 9000, Belgium

Full list of author information is available at the end of the article
}

syndrome. Type I Stickler syndrome (STL1) is associated with mutations in the COL2A1 gene encoding type II collagen [5], while mutations in COL11A1 and COL11A2 encoding type XI collagen, are associated with type II (STL2) [6] and type III Stickler syndrome (STL3) [7] respectively. Autosomal recessive Stickler syndrome has been described in some families with mutations in COL9A1 (STL4) [8] and COL9A2 (STL5) [9] encoding type IX collagen.

Phenotypic distinction between patients with mutations in different causative genes is possible to a certain degree. For example, STL3 does not exhibit ocular abnormalities, as COL11A2 is not expressed in the vitreous [10]. Another example is the vitreous anomaly, which is mostly 'membranous' in STL1 and 'beaded' in STL2 [6]. However, large phenotypic difference, not explained

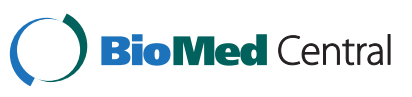


solely by the affected gene, still exists. Even within one family or within unrelated families carrying the same mutation, clinical expression shows high variability [11].

In 1965, Stickler et al. described a family with joint manifestations and progressive myopia, associated with retinal detachment in the first decade of life and resulting in blindness [1]. In an additional report, mild sensorineural hearing impairment was added to the features typical of this syndrome [12]. Subsequently, hearing impairment has commonly been reported as a symptom of Stickler syndrome, though detailed descriptions are scarce and few studies are primarily focused on the auditory phenotype. Hearing loss in STL1 seems to be present in about $60 \%$ of affected persons and is likely to be sensorineural $[13,14]$. STL2 and STL3 are associated with hearing loss occurring more frequently and being more severe [13]. The pathogenesis of this sensorineural hearing loss is not well understood. Associated findings are a hypermobile tympanic membrane [14], and cleft palate resulting in middle ear effusion and conductive hearing loss.

Because of the large interfamilial and intrafamilial phenotypic variability observed in Stickler patients, clinicians are unfortunately unable to predict whether their patients will develop hearing loss. In this article, we aim to review the literature about hearing impairment in all types of Stickler syndrome. The auditory features of patients found by systematic review is described and prevalences, obtained through meta-analysis, are provided. Hearing loss is also linked to the causal gene, mutation type and mutation effect in order to find correlations. This article offers an up-to-date overview of hearing loss in Stickler syndrome, correlated with the genotype.

\section{Materials and methods Search strategy}

A systematic review was performed in order to analyze the auditory features in Stickler syndrome. We intended to find all papers describing the phenotype with regard to hearing in Stickler patients, along with their genotype.

Relevant articles were searched using the electronic databases of PubMed and Web of Science from inception to 31 July 2012. Considering the different notations (e.g. Stickler syndrome vs. Stickler's syndrome), following search strings were used: "stickler" and "arthroophthalmopath* OR arthroophthalmopath*". To exclude non-relevant articles, the queries were restricted to title/ abstract in Pubmed and topic in Web of Science. Reference lists of the retrieved articles were hand-searched for additional papers. A bibliography with the citations retrieved from the abovementioned searches was created using EndNote X4 (Thomson Reuters, New York, USA). Duplicates and non-English articles were removed both automatically and manually, as well as short conference proceedings. One investigator (FA) conducted this first selection of articles, under the auspices of the principal investigators (EDL, ID), in order to find articles for review purposes.

To perform a meta-analysis, the eligibility of papers was assessed based on two main inclusion criteria: the indication of the presence or absence of hearing impairment in Stickler and Stickler-like patients and the finding of a causative mutation. Probable Marshall phenotype and autosomal recessive otospondylomegaepiphyseal dysplasia (OSMED) patients were excluded, as well as patients in whom only linkage to a gene was demonstrated. In case of doubt, mutual agreement between the authors was achieved.

\section{Statistical analysis}

The following data, if available, were extracted from articles meeting the inclusion criteria: study characteristics (authors, year of publication, study design and methods, original data or described elsewhere), patient attributes (family and age, relevant comorbidities), hearing features (hearing impairment, type and severity of hearing loss, additional auditory data, palatal defects) and mutation (mutated gene, mutation type and location, mutation effect). When a patient or family was described in different papers, the most informative paper was used for data collection.

Calculations were performed using SPSS version 19 (SPSS Inc., Chicago, USA). Where appropriate, statistical tests were used to assess statistical significance. Exons of COL2A1 were numbered according to the GenBank database [GenBank:L10347]. In order to avoid selection bias (proportionally greater importance of larger families), some calculations were repeated in an analysis where all families were equally weighted. In the subtypes of Stickler syndrome where sufficient audiograms of different patients could be collected, an average audiogram or even an age-related typical audiogram (ARTA) of the respective subtype was calculated.

The study was conducted taking into account the instructions of the PRISMA statement for reporting systematic reviews [15] and of the MOOSE group for reporting a meta-analysis of observational studies [16].

\section{Results}

\section{Search results}

A flow diagram of the search process is depicted in Figure 1. For review purposes, 451 articles were read to extract interesting data described in the discussion. Ultimately, 46 articles were included in the meta-analysis (see Additional file 1: Table S1 for description of the included articles) $[3,5,8,9,11,17-57]$. Seven papers that fulfilled the inclusion criteria were withheld because of different reasons. Five of them contained data of patients being 


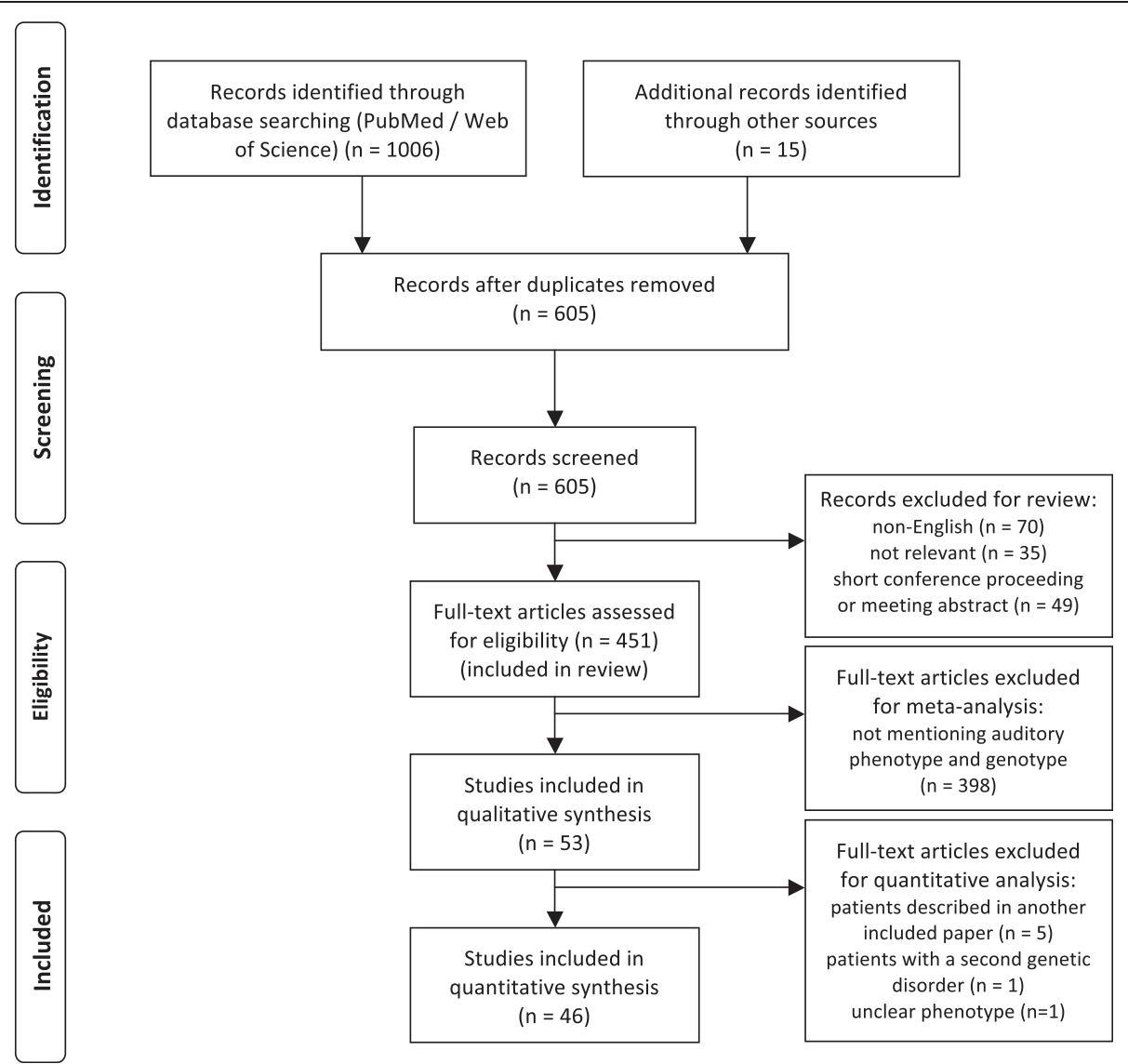

Figure 1 PRISMA flow diagram, showing the overview of the search process. Schematic overview of the various steps involved in the search process, according to the PRISMA guidelines. We read 451 articles about Stickler syndrome, whose content, if relevant, could be included in the discussion. Data from 46 articles, meeting the inclusion criteria of the meta-analysis, are used to provide accurate prevalences about hearing loss in the results section of this article.

described more thoroughly in another paper [6,7,58-60], one reported a patient suffering from a second genetic disorder that could as well result in hearing loss [61], and hearing impairment in another one was unclear [62]. Quality of the included papers was assessed (Additional file 1: Table S1), but none of them were rejected based on quality properties alone, in order to obtain a large population in which it is possible to draw firm conclusions. In the 46 included articles, a total of 313 individual patients of 102 families were found to meet the inclusion criteria. Nine additional families with phenotypic and genotypic information, but without individual data, were added, resulting in 111 different Stickler families.

\section{Auditory phenotype in Stickler syndrome}

Mean age of the individual Stickler patients was 26.4 years (standard deviation 19.49, age was given in 221 patients), and gender distribution was $55.2 \%$ female versus $44.8 \%$ male persons (gender was provided in 210 patients).

Hearing loss was reported in 197 of the 313 patients (62.9\%, Figure 2). In 177 cases, the type of hearing loss was mentioned. In this group 120 patients (67.8\%) showed a pure sensorineural hearing loss. Mixed hearing loss was present in 32 persons (18.1\%), and 25 patients (14.1\%) suffered from conductive hearing loss. Consequently, a conductive component (conductive and mixed hearing loss) was present in $32.2 \%$ of the hearing-impaired patients. Figure 3 shows the distribution of prevalence and type of hearing loss among different age groups (age was available in 221 patients). When splitting up the hearing-impaired population in which age is available into a group of children (below 18 years) and a group of adults (aged 18 and older), hearing loss included a conductive component in $46.6 \%(27 / 58)$ in the younger group versus $23.3 \%(20 / 86)$ in the older group ( $\mathrm{p}=0.004$, Fisher exact test). Gender did not significantly alter the prevalence of hearing loss, not even at high age ( $\mathrm{p}=0.31$ for the whole group, Fisher exact test). Regarding severity, hearing loss was mild in $44.6 \%$, moderate in $36.6 \%$ and severe in $18.8 \%$ of the subjects, although it is often not clear which definitions for severity were applied. No profound hearing loss was observed. In patients with mixed hearing loss, severity was 


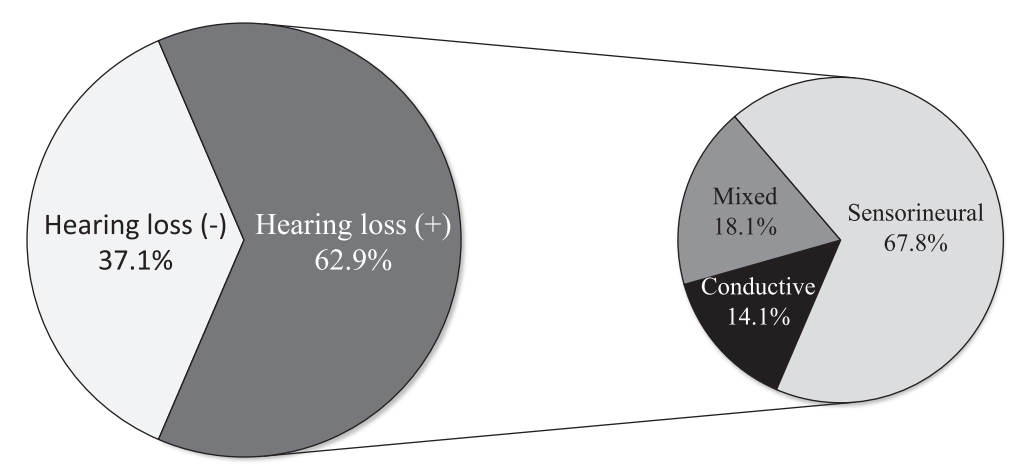

Figure 2 The prevalence and type of hearing loss in Stickler syndrome. The percentages of the 313 included Stickler patients without and with hearing loss are displayed. Of the hearing-impaired patients, a subdivision into conductive, mixed and sensorineural hearing loss is provided. The group of hearing-impaired patients in which the type was not mentioned (6.4\% of the total population), was proportionally divided among the three hearing loss groups.

often higher; however, a conductive component can only be moderate at worst.

A palatal defect (cleft palate, submucous cleft, higharched palate) was present in $42.6 \%(121 / 284)$ of the studied population. Of the patients with a palatal defect, $73.6 \%$ (89/121) were hearing-impaired, compared to $54.0 \%$ (88/ $163)$ without palatal defect $(\mathrm{p}<0.001$, Fisher exact test). As seen in Table 1, this difference can largely be attributed to the higher prevalence of conductive and mixed hearing loss, while the percentage of sensorineural hearing loss is comparable between the two groups.

\section{Auditory phenotype in different Stickler genotypes}

STL1 occurred in 224 cases (71.6\%), while this was 40 (12.8\%) for STL2, 34 (10.9\%) for STL3, 7 (2.2\%) for STL4 and $8(2.6 \%)$ for STL5. For each Stickler gene, the distinct percentage and type of hearing loss is shown in Figure 4.
Severity of hearing loss was mostly reported to be mild to moderate for STL1, STL2 and STL5. In STL3 and STL4, predominantly moderate and severe hearing loss was found respectively. An ARTA for STL3 and an average audiogram for STL4 are provided in Figure 5, as well as an ARTA for Stickler syndrome in general. Palatal defects were present in $44.3 \%, 48.7 \%$ and $44.8 \%$ in STL1, STL2 and STL3, respectively. Patients with a collagen IX mutation (STL4 and STL5) did not exhibit palatal defects.

The mutations of 36 STL1 patients were expected to result in a dominant-negative effect, while these of 174. STL1 patients were supposed to induce nonsense-mediated decay (mutation effect was available in 210 STL1 patients). Hearing loss was present in $47.2 \%$ of the first group versus $52.9 \%$ of the second $(\mathrm{p}=0.59$, Fisher exact test), and a palatal defect occurred in $16.7 \%$ versus $46.9 \%(\mathrm{p}=0.002$, Fisher exact test). No statistical significance was observed

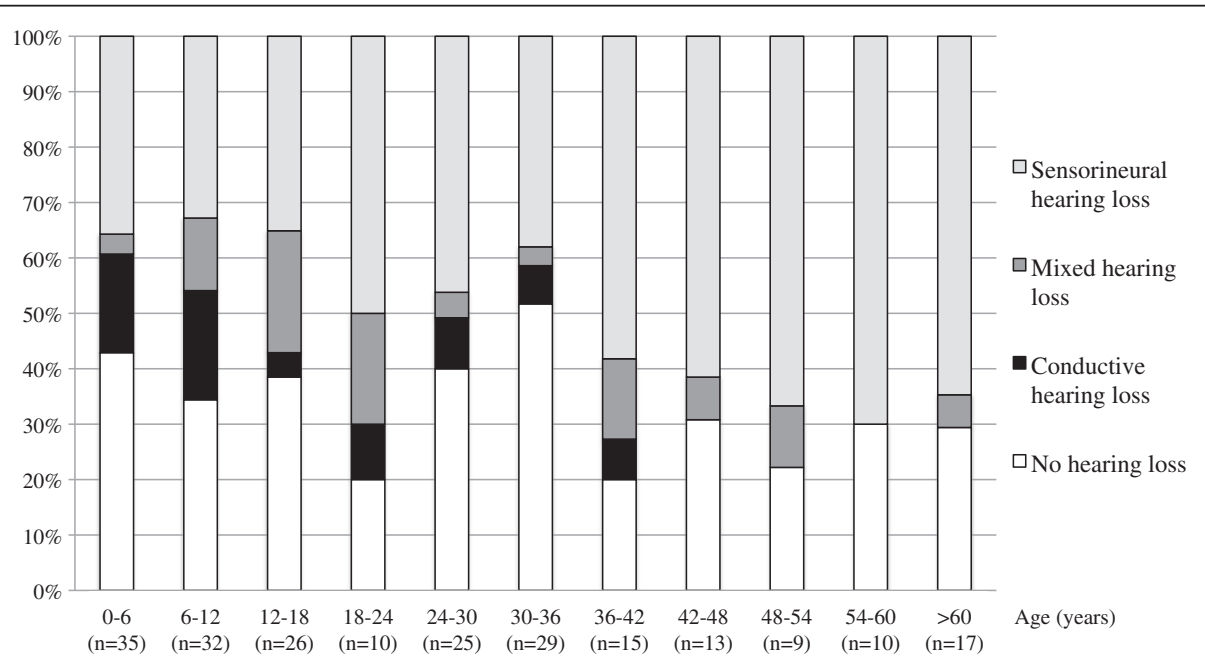

Figure 3 Prevalences of hearing phenotype in Stickler patients, divided into age groups. The percentages of hearing loss and its type for each age group can be derived from this diagram. The group of hearing-impaired patients in which the type was not mentioned (6.4\%), was proportionally divided among the three hearing loss groups. 
Table 1 Prevalence and type of hearing loss in patients with and without palatal defect

\begin{tabular}{llll}
\hline & $\begin{array}{l}\text { Palatal } \\
\text { defect } \\
(\mathbf{n = 1 2 1 )}\end{array}$ & $\begin{array}{l}\text { No palatal } \\
\text { defect } \\
(\mathbf{n}=\mathbf{1 6 3 )}\end{array}$ & p value \\
\hline No hearing loss & $26.4 \%$ & $46.0 \%$ & $<\mathbf{0 . 0 0 1}$ \\
\hline Conductive hearing loss & $13.6 \%$ & $4.2 \%$ & $\mathbf{0 . 0 0 8}$ \\
\hline Mixed hearing loss & $20.0 \%$ & $6.3 \%$ & $<\mathbf{0 . 0 0 1}$ \\
\hline Sensorineural hearing loss & $40.0 \%$ & $43.5 \%$ & 0.544
\end{tabular}

This table shows the percentages of each type of hearing phenotype for patients with and without palatal defect separately. Palatal defects include cleft palate, submucous cleft and high-arched palate. The group of hearingimpaired patients in which the type was not mentioned, was proportionally divided among the three hearing loss groups. Stickler patients with a palatal defect exhibit significantly more hearing loss, and this can be attributed to the higher number of patients with conductive and mixed hearing loss.

between location of the mutation in the collagen gene (exon/intron number) and the presence of hearing loss ( $\mathrm{p}=0.44$, Mann-Whitney $U$ test; mean exon number of 26.0 when hearing loss is absent vs. 28.8 when present), but differences were seen between mutation location and palatal defects $(\mathrm{p}=0.01$, Mann-Whitney $\mathrm{U}$ test; mean exon number of 24.4 when palatal defect is absent vs. 30.4 when present).

\section{Auditory phenotype and genotype in family study}

When the 111 different families are equally weighted, regardless of the number of affected family members, the prevalence of hearing loss was $60.1 \%$. Within these hearing-impaired subjects, the percentages of sensorineural, mixed and conductive hearing loss were $60.4 \%$, $18.3 \%$ and $21.3 \%$, respectively. The prevalence of palatal defects was 51.5\%. STL1 occurred in 85 families (76.6\%), while this was 17 (15.3\%) for STL2, 5 (4.5\%) for STL3, 3 (2.7\%) for STL4 and 1 (0.9\%) for STL5.

\section{Discussion}

Hearing loss is a common feature in Stickler syndrome, expressed in $63 \%$ of all patients. About two-thirds of these hearing-impaired patients express a purely sensorineural loss. This prevalence increases with advancing age, most probably not only due to age-related hearing loss. Conductive and mixed hearing loss is mostly found in children with Stickler syndrome and in patients with a history of a palatal defect, but can also be present in adults. These results are consistent with those of other authors studying hearing features in a large group of Stickler patients $[14,63]$. As the distinct disease-causing collagen genes in Stickler syndrome lead to a different auditory phenotype, hearing features are described for the involved genes separately.

About $75 \%$ of all Stickler patients have type I Stickler syndrome, caused by mutations in COL $2 A 1$. This type has the best prognosis concerning hearing: $52.2 \%$ of the affected persons exhibit hearing loss, which is mostly sensorineural. As in the other dominant Stickler types, conductive and mixed hearing loss may also be present, especially in young children and with a palatal defect. The sensorineural hearing loss is often reported to affect mainly the higher frequencies. Progression of hearing impairment is described, but it is unclear whether the high-frequency hearing loss in STL1 progresses beyond presbyacusis. It is generally mild to moderate and does not evolve to severe hearing impairment.

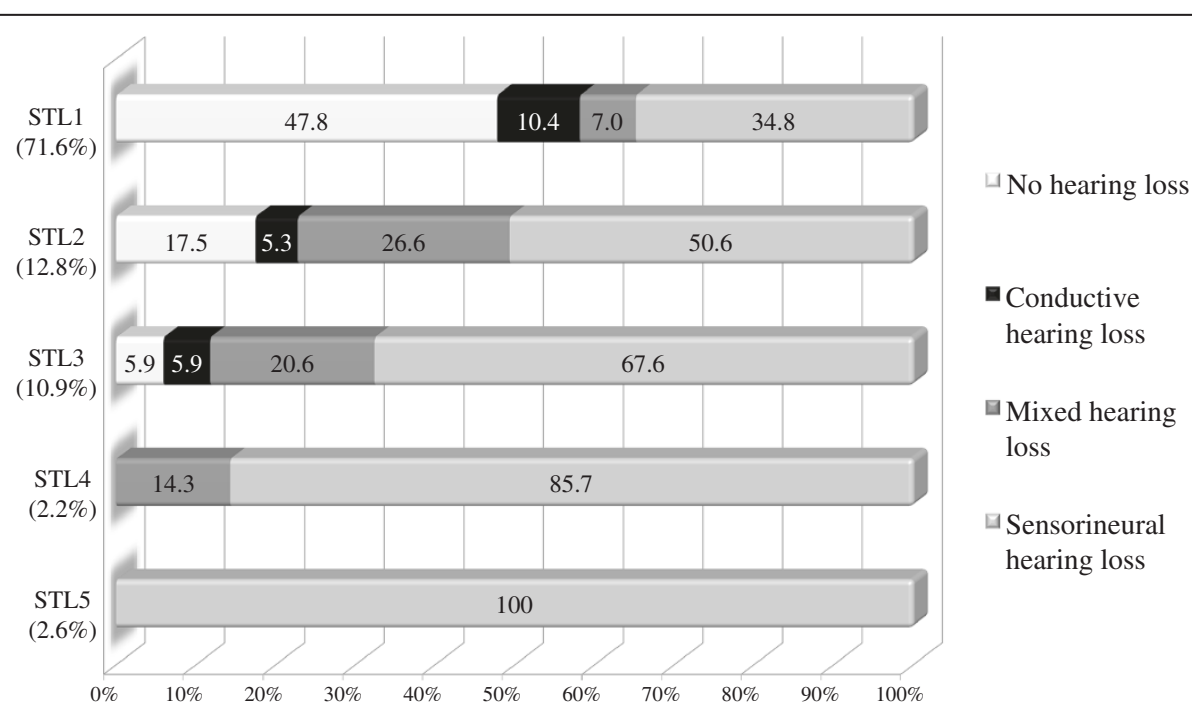

Figure 4 Hearing phenotype in distinct Stickler types. The percentages of hearing loss and its type for each type of Stickler syndrome (according to the affected gene) are shown in this figure. The group of hearing-impaired patients in which the type was not mentioned (6.4\%), was proportionally divided among the three hearing loss groups. 


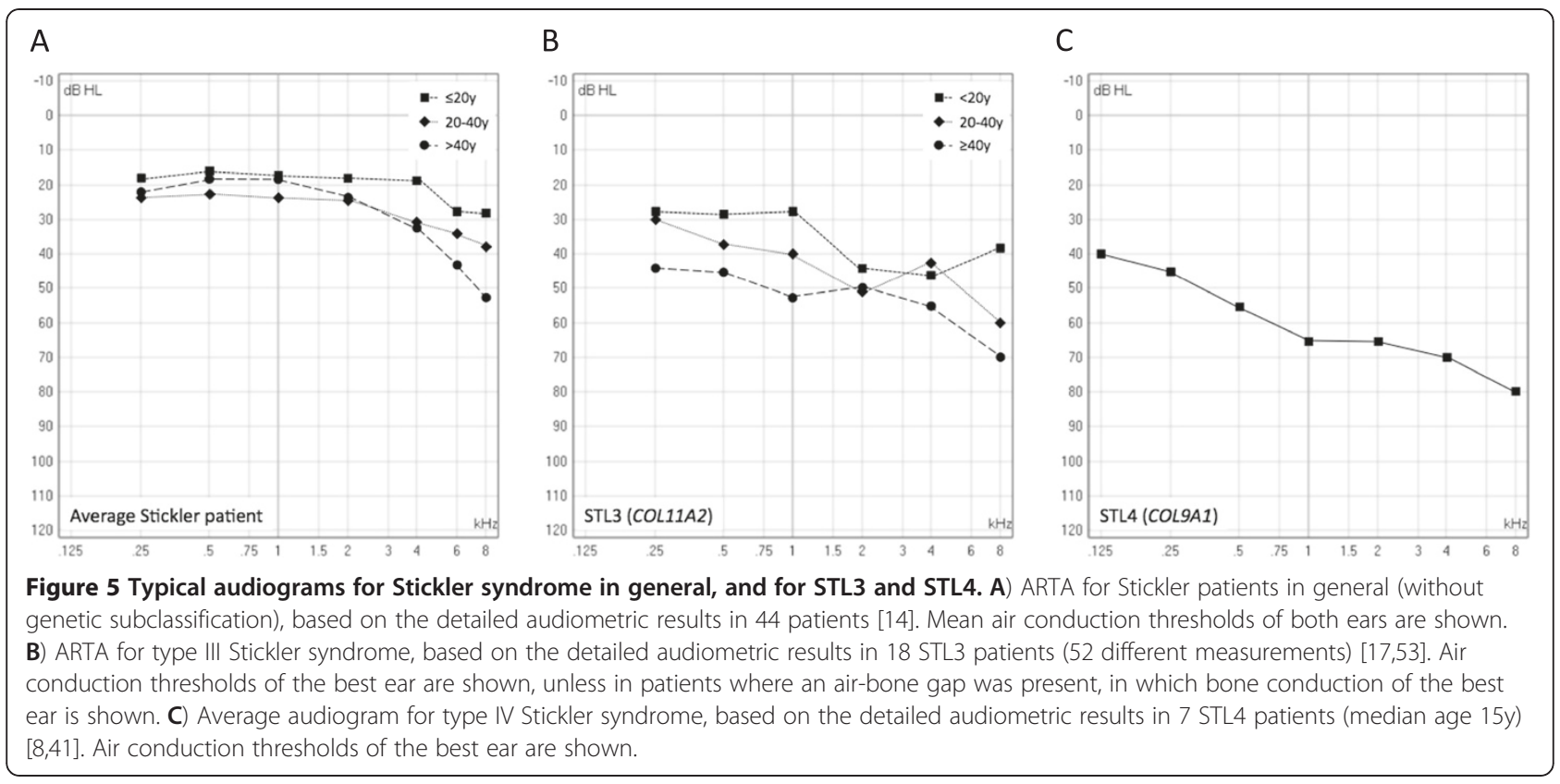

COL2A1 is present in numerous inner ear structures, which may explain why mutations in this gene can cause hearing loss [64]. Stickler syndrome is just one of the clinical expressions that belongs to the spectrum of type II collagenopathies, ranging from the lethal achondrogenesis type II, to mild forms of solely ocular or skeletal manifestations. Some of these expressions are also associated with hearing loss. However, large variability, interfamilial as well as intrafamilial, exists. Our study failed to find significant differences in STL1 hearing loss due to mutation effect and location. Therefore, it can be suggested that modifier genes and environmental factors may also play a role in the development of hearing loss.

Type II Stickler syndrome (COL11A1) is the second most common type of Stickler syndrome. It is estimated to be present in about $15 \%$ of the probands with Stickler syndrome. Hearing loss is found in $82.5 \%$ of these patients; most of them have sensorineural loss, but again, also conductive and mixed hearing impairment have been described. Hearing loss in STL2 seems to be more pronounced than in STL1, and is already apparent at young age. It is not clear whether the higher frequencies are predominantly affected and whether or not the hearing loss progresses with age.

Marshall syndrome is allelic with STL2 and both diseases show considerable overlap. Most of the Marshall patients also develop early-onset, high-frequency sensorineural hearing loss progressing to severe hearing impairment at older ages.

Type XI collagen is associated with type II collagen and hybridization of their gene products can be found in the lateral wall of the developing mouse cochlea. It is suggested that mutations in COL11A1 may influence hearing due to their effects on the formation and function of the tectorial membrane [65]. Until now, it is not yet clarified how mutations in this gene can cause the above-mentioned type of hearing loss. However, although not quantitatively important in the inner ear, COL11A1 protein seems to be crucial for normal hearing.

In type III Stickler syndrome (COL11A2), hearing loss was found in $94.1 \%$ of the patients. It can even be suggested that all STL3 patients have some degree of hearing loss, because the two subjects not exhibiting hearing problems, were not audiometrically tested [51]. Sensorineural hearing impairment is, as in STL1 and STL2, most prevalent, and seems to be more pronounced in the middle and higher frequencies. However, there is no typical audiometric configuration and a conductive component may also be present [17]. Hearing loss in STL3 is likely to have a childhood onset and does not or just slightly progress; its severity is mostly moderate.

Mutations in COL11A2 may also result in nonsyndromic hearing loss as in DFNA13 and DFNB53. Hearing impairment in DFNA13 is non-progressive, probably prelingual, and represented by a U-shaped to slightly down-sloping audiogram [66]. Interestingly, one family with DFNA13 seemed to be protected against presbyacusis [67], which might also be present in type III Stickler syndrome [53]. DFNB53-related hearing impairment results in a prelingual, severe, U-shaped audiogram [68]. Autosomal recessive OSMED is caused by mutations in COL11A2 as well. This syndrome is 
characterized by severe sensorineural hearing loss, enlarged epiphyses, shortness of the limbs and orofacial features comparable to those of Stickler syndrome [69].

Previous studies revealed the disruption of collagen fibrils within the tectorial membrane to be the only observed morphological inner ear change of COL11A2 $-/-$ mice, resulting in a frequency-independent, cochlear loss of 30-50 dB [66,70]. Consequently, collagen type XI is important to maintain the tectorial membrane integrity, as both COL11A1 and COL11A2 mutations may cause hearing loss due to changed morphology of this inner ear structure.

Four different families with autosomal recessive Stickler syndrome have been described, all exhibiting a mutation in genes encoding type IX collagen $[8,9,41]$. The involved patients showed a similar pattern of hearing impairment: a slightly progressive sensorineural hearing loss with early onset, more pronounced at higher frequencies. Severity was moderate to severe in STL4 (COL9A1) and mild to moderate in STL5 (COL9A2). None of these patients showed palatal defects.

These results are consistent with animal studies, which demonstrated type IX collagen, in addition to type XI collagen, as an important factor in maintaining the integrity of collagen fibers in the tectorial membrane [71]. Type IX collagen knock-out mice showed progressive hearing loss and morphological changes of the tectorial membrane, starting in the basal turn of the cochlea and progressing towards the apical turn [72]. This is in line with the observed hearing loss in recessive Stickler syndrome: progressive and initially more pronounced at higher frequencies.

Besides Stickler syndrome, mutated type IX collagen can also result, inter alia, in multiple epiphyseal dysplasia (MED), a skeletal dysplasia not associated with hearing loss. However, MED has been attributed to heterozygous splice site mutations in type IX collagen genes, resulting in inframe exon skipping situated in the third collagenous domain (COL3) and effectuating a dominant-negative effect $[41,73]$. In contrast, the mutations found in STL4 and STL5 are more spread out over the gene and are supposed to result in nonsense-mediated decay.

Another, rather specific, auditory finding in Stickler syndrome is hypermobility of the tympanic membrane, measured by tympanometry. In up to $46 \%$ of Stickler patients, type $A_{D}$ tympanograms were obtained [3,11,14]. Most of these patients probably had STL1, because tympanic hypermobility was less seen in STL2 patients [74]. Hypermobile middle ear system may be the result of frequent otitis media with ventilation tubes and/or tympanic perforations, but the collagen defect in STL1 may also contribute. Indeed, type II collagen is observed in the ossicular joints [75] and is the most abundant collagen of the tympanic lamina propria [76].
In Stickler patients, language and speech may be affected by hearing impairment and by the typical facial morphology, including cleft palate, especially if these problems are not recognized early and optimally treated. However, speech audiometry showed perception and discrimination scores consistent with the obtained pure tone thresholds [17].

Little attention is paid to the vestibular system of Stickler patients. Ocular and skeletal manifestations can contribute to instability complaints and may interfere with some of the balance tests [14]. Five tested children and 1 adult have been identified as having abnormal peripheral vestibular function combined with hearing loss [77]. In their review, Admiraal et al. stated that Stickler patients rarely complain about vestibular symptoms, though vestibular deficits may be objectified [13]. Future research should also focus on the vestibular system, as this may render novel insight into the pathophysiology of the syndrome.

Temporal bone imaging in Stickler syndrome mostly does not reveal middle or inner ear structural anomalies (5 cases mentioned by Rai et al. [78], 19 cases in Szymko-Bennett et al. [14]). In sporadic cases, ossicular defects [4] and fixations [21] were reported. Again, more studies need to be performed to draw strong conclusions about temporal bone anomalies in Stickler syndrome.

Conductive hearing loss in adults is sporadically reported and can be due to stapes ankylosis [21], chronic ear disease resulting in mastoidectomy surgery $[17,43]$, and eustachian tube dysfunction, predominantly in patients with a history of cleft palate. With the latter in mind, clinicians should also be aware of cholesteatoma development in Stickler patients.

Overall, when interpreting these results, some comments have to be made. A family analysis was performed in order to avoid bias due to the greater importance of families in which a large number of affected family members are described. When the different families are equally weighted, only minor differences could be found concerning the auditory phenotype. To avoid reporting bias, we also included papers in which hearing features were not extensively described or studied. However, quality analysis of the studied articles revealed that hearing loss seems to be found more in studies with auditory testing compared to history alone. Consequently, we confirm that clinicians cannot rely on patients' history of hearing capacity alone, and that regular hearing tests in Stickler patients are recommended, regardless of symptom reporting [79]. Future research should focus on progression of hearing loss and the audiometric configuration, especially the presence and practical influence of high-frequency sensorineural loss. These results may even contribute in unravelling the pathophysiology of presbyacusis. Novel Stickler studies should take into account age-related hearing loss, as few studies to 
date did, and a uniform classification system should be used. It would also be interesting to study other relevant topics, such as imaging of the middle and inner ear structures, and functioning of the vestibular system, as these are not well described in literature.

\section{Conclusions}

Hearing loss is a common finding in Stickler syndrome, affecting more than half of the patients. Sensorineural hearing loss predominates, but conductive and mixed hearing loss may also be present, especially in young children and in patients with an associated palatal defect. There are differences in prevalence of hearing loss for the different types of Stickler syndrome and each genotype shows a different pattern of hearing loss. Hearing loss in STL1 is present in half of the patients and is usually mild to moderate, while hearing impairment in STL2 and STL3 is more common, more severe, and present at younger age. However, we have to be aware of large phenotypic variation. Given the high prevalence of hearing loss in Stickler patients, referral for hearing assessment and regular auditory follow-up is required upon diagnosis. If hearing impairment is detected, site of lesion testing will guide treatment options, such as ventilation tube insertion and hearing aid fitting. Close attention to the hearing system is particularly important because most of the patients are already visually impaired.

\section{Additional file}

\section{Additional file 1: Table S1. List of articles included in the}

meta-analysis. This table shows the articles from which data were extracted to use in the results section. For each article, the number of patients and families included, and the type of Stickler syndrome is mentioned, as well as some methodological features. References are numbered according to and can be found in the original article.

\section{Abbreviations}

STL1: Stickler syndrome type I (COL2A1); STL2: Stickler syndrome type ॥ (COL11A1); STL3: Stickler syndrome type III (COL11A2); STL4: Stickler syndrome type IV (COL9A1); STL5: Stickler syndrome type V (COL9A2);

OSMED: Otospondylomegaepiphyseal dysplasia; ARTA: Age-related typical audiogram; DFNA: Deafness, autosomal dominant; DFNB: Deafness, autosomal recessive; MED: Multiple epiphyseal dysplasia.

\section{Competing interests}

The authors declare that they have no competing interests.

\section{Authors' contributions}

FA collected the data, performed the statistical analysis and drafted the manuscript. ID and EDL participated in the design of the study, reviewed the data collection independently and made contributions to the draft of the manuscript. FM was involved in genetic data interpretation and in drafting the manuscript. All authors read and approved the final manuscript.

\section{Acknowledgements}

FA holds a Ph.D. fellowship of the Research Foundation Flanders (FWO Vlaanderen), Belgium. FM is a postdoctoral fellow supported by the Research Foundation Flanders (FWO Vlaanderen), Belgium.

\section{Author details}

'Department of Otorhinolaryngology, 1P1, Ghent University / Ghent University Hospital, De Pintelaan 185, Ghent 9000, Belgium. ${ }^{2}$ Department of Medical Genetics, Ghent University Hospital, De Pintelaan 185, Ghent 9000, Belgium.

Received: 27 August 2012 Accepted: 22 October 2012

Published: 30 October 2012

\section{References}

1. Stickler GB, Belau PG, Farrell FJ, Jones JD, Pugh DG, Steinberg AG, Ward LE: Hereditary progressive arthro-ophthalmopathy. Mayo Clin Proc 1965, 40:433-455.

2. Robin NH, Moran RT, Warman M, Ala-Kokko L: Stickler Syndrome. 1993 Jun 9 [Updated 2011 Nov 3]. In GeneReviews ${ }^{T M}$ [Internet]. Seattle (WA). Edited by Pagon RA, Bird TC, Dolan CR, et al. Seattle: University of Washington; 2011.

3. Rose PS, Levy HP, Liberfarb RM, Davis J, Szymko-Bennett Y, Rubin BI, Tsilou E, Griffith AJ, Francomano CA: Stickler syndrome: clinical characteristics and diagnostic criteria. Am J Med Genet A 2005, 138A(3):199-207.

4. Temple IK: Stickler's syndrome. J Med Genet 1989, 26(2):119-126.

5. Ahmad NN, Ala-Kokko L, Knowlton RG, Jimenez SA, Weaver EJ, Maguire Jl, Tasman W, Prockop DJ: Stop codon in the procollagen II gene (COL2A1) in a family with the Stickler syndrome (arthro-ophthalmopathy). Proc Natl Acad Sci U S A 1991, 88(15):6624-6627.

6. Richards AJ, Yates JR, Williams R, Payne SJ, Pope FM, Scott JD, Snead MP: A family with Stickler syndrome type 2 has a mutation in the COL11A1 gene resulting in the substitution of glycine 97 by valine in alpha 1 (XI) collagen. Hum Mol Genet 1996, 5(9):1339-1343.

7. Vikkula M, Mariman EC, Lui VC, Zhidkova NI, Tiller GE, Goldring MB, van Beersum SE, de Waal Malefijt MC, van den Hoogen FH, Ropers HH, et al: Autosomal dominant and recessive osteochondrodysplasias associated with the COL11A2 locus. Cell 1995, 80(3):431-437.

8. Van Camp G, Snoeckx RL, Hilgert N, van den Ende J, Fukuoka H, Wagatsuma M, Suzuki H, Smets RM, Vanhoenacker F, Declau F, et al: A new autosomal recessive form of Stickler syndrome is caused by a mutation in the COL9A1 gene. Am J Hum Genet 2006, 79(3):449-457.

9. Baker S, Booth C, Fillman C, Shapiro M, Blair MP, Hyland JC, Ala-Kokko L: A loss of function mutation in the COL9A2 gene causes autosomal recessive Stickler syndrome. Am J Med Genet A 2011, 155A(7):1668-1672.

10. Mayne R, Brewton RG, Mayne PM, Baker JR: Isolation and characterization of the chains of type $\mathrm{V} /$ type $\mathrm{XI}$ collagen present in bovine vitreous. J Biol Chem 1993, 268(13):9381-9386.

11. Liberfarb RM, Levy HP, Rose PS, Wilkin DJ, Davis J, Balog JZ, Griffith AJ, Szymko-Bennett YM, Johnston JJ, Francomano CA, et al: The Stickler syndrome: genotype/phenotype correlation in 10 families with Stickler syndrome resulting from seven mutations in the type II collagen gene locus COL2A1. Genet Med 2003, 5(1):21-27.

12. Stickler GB, Pugh DG: Hereditary Progressive Arthro-Ophthalmopathy .2. Additional Observations on Vertebral Abnormalities a Hearing Defect and a Report of a Similar Case. Mayo Clin Proc 1967, 42(8):495.

13. Admiraal RJ, Szymko YM, Griffith AJ, Brunner HG, Huygen PL: Hearing impairment in Stickler syndrome. Adv Otorhinolaryngol 2002, 61:216-223.

14. Szymko-Bennett YM, Mastroianni MA, Shotland LI, Davis J, Ondrey FG, Balog JZ, Rudy SF, McCullagh L, Levy HP, Liberfarb RM, et al: Auditory dysfunction in Stickler syndrome. Arch Otolaryngol Head Neck Surg 2001, 127(9):1061-1068.

15. Moher D, Liberati A, Tetzlaff J, Altman DG: Preferred reporting items for systematic reviews and meta-analyses: the PRISMA statement. BMJ 2009, 339:b2535.

16. Stroup DF, Berlin JA, Morton SC, Olkin I, Williamson GD, Rennie D, Moher D, Becker BJ, Sipe TA, Thacker SB: Meta-analysis of observational studies in epidemiology: a proposal for reporting. Meta-analysis Of Observational Studies in Epidemiology (MOOSE) group. JAMA 2000, 283(15):2008-2012.

17. Admiraal RJ, Brunner HG, Dijkstra TL, Huygen PL, Cremers CW: Hearing loss in the nonocular Stickler syndrome caused by a COL11A2 mutation. Laryngoscope 2000, 110(3 Pt 1):457-461.

18. Ahmad NN, Dimascio J, Knowlton RG, Tasman WS: Stickler syndrome. A mutation in the nonhelical 3 / end of type II procollagen gene. Arch Ophthalmol 1995, 113(11):1454-1457.

19. Annunen $\mathrm{S}$, Korkko J, Czarny M, Warman ML, Brunner HG, Kaariainen $\mathrm{H}$, Mulliken JB, Tranebjaerg L, Brooks DG, Cox GF, et al: Splicing mutations of 
54-bp exons in the COL11A1 gene cause Marshall syndrome, but other mutations cause overlapping Marshall/Stickler phenotypes. Am J Hum Genet 1999, 65(4):974-983.

20. Avcin T, Makitie O, Susic M, Miller S, Thorne C, Tenenbaum J, Laxer RM, Cole WG: Early-onset osteoarthritis due to otospondylomegaepiphyseal dysplasia in a family with a novel splicing mutation of the COL11A2 gene. J Rheumatol 2008, 35(5):920-926.

21. Baijens LW, De Leenheer EM, Weekamp HH, Cruysberg JR, Mortier GR, Cremers CW: Stickler syndrome type I and Stapes ankylosis. Int J Pediatr Otorhinolaryngol 2004, 68(12):1573-1580

22. Ballo R, Beighton PH, Ramesar RS: Stickler-like syndrome due to a dominant negative mutation in the COL2A1 gene. Am J Med Genet 1998, 80(1):6-11.

23. Brown DM, Nichols BE, Weingeist TA, Sheffield VC, Kimura AE, Stone EM: Procollagen II gene mutation in Stickler syndrome. Arch Ophthalmol 1992, 110(11):1589-1593.

24. De Keyzer TH, De Veuster I, Smets RM: Stickler syndrome: an underdiagnosed disease. Report of a family. Bull Soc Belge Ophtalmol 2011, 318:45-49.

25. Donoso LA, Edwards AO, Frost AT, Ritter R, Ahmad NN, Vrabec T, Rogers J, Meyer D: Identification of a stop codon mutation in exon 2 of the collagen $2 \mathrm{~A} 1$ gene in a large stickler syndrome family. Am J Ophthalmol 2002, 134(5):720-727.

26. Edwards TL, Burt BO, Black GC, Perveen R, Kearns LS, Staffieri SE, Toomes C, Buttery RG, Mackey DA: Familial retinal detachment associated with COL2A1 exon 2 and FZD4 mutations. Clin Experiment Ophthalmol 2012, 40 (5):476-483

27. Faber J, Winterpacht A, Zabel B, Gnoinski W, Schinzel A, Steinmann B, Superti-Furga $A$ : Clinical variability of Stickler syndrome with a COL2A1 haploinsufficiency mutation: implications for genetic counselling. J Med Genet 2000, 37(4):318-320.

28. Freddi S, Savarirayan R, Bateman JF: Molecular diagnosis of Stickler syndrome: a COL2A1 stop codon mutation screening strategy that is not compromised by mutant mRNA instability. Am J Med Genet 2000, 90 (5):398-406

29. Fujiwaki T, Nishimura G, Ohashi H, Ito K, Kazama S, Ishioka C: Postnatal remission of ocular, auditory, and somatic findings in Stickler syndrome. Pediatr Int 2004, 46(5):605-608.

30. Gerth-Kahlert C, Grisanti S, Berger E, Hohn R, Witt G, Jung U: Bilateral vitreous hemorrhage in a newborn with Stickler syndrome associated with a novel COL2A1 mutation. J AAPOS 2011, 15(3):311-313.

31. Go SL, Maugeri A, Mulder JJ, van Driel MA, Cremers FP, Hoyng CB: Autosomal dominant rhegmatogenous retinal detachment associated with an Arg453Ter mutation in the COL2A1 gene. Invest Ophthalmol Vis Sci 2003, 44(9):4035-4043.

32. Hoornaert KP, Dewinter C, Vereecke I, Beemer FA, Courtens W, Fryer A, Fryssira H, Lees M, Mullner-Eidenbock A, Rimoin DL, et al: The phenotypic spectrum in patients with arginine to cysteine mutations in the COL2A1 gene. J Med Genet 2006, 43(5):406-413.

33. Hoornaert KP, Vereecke I, Dewinter C, Rosenberg T, Beemer FA, Leroy JG, Bendix L, Bjorck $\mathrm{E}$, Bonduelle $\mathrm{M}$, Boute $\mathrm{O}$, et al: Stickler syndrome caused by COL2A1 mutations: genotype-phenotype correlation in a series of 100 patients. Eur J Hum Genet 2010, 18(8):872-880

34. Korkko J, Ritvaniemi P, Haataja L, Kaariainen H, Kivirikko Kl, Prockop DJ, Ala-Kokko L: Mutation in type II procollagen (COL2A1) that substitutes aspartate for glycine alpha 1-67 and that causes cataracts and retina detachment: evidence for molecular heterogeneity in the Wagner syndrome and the Stickler syndrome (arthro-ophthalmopathy). Am J Hum Genet 1993, 53(1):55-61.

35. Leung L, Hyland JC, Young A, Goldberg MF, Handa JT: A novel mutation in intron 11 of the COL2A1 gene in a patient with type 1 Stickler syndrome. Retina 2006, 26(1):106-109.

36. MacRae ME, Patel DV, Richards AJ, Snead MP, Tolmie J, Lee WR: Type 1 Stickler syndrome: a histological and ultrastructural study of an untreated globe. Eye (Lond) 2006, 20(9):1061-1067.

37. Majava M, Hoornaert KP, Bartholdi D, Bouma MC, Bouman K, Carrera M, Devriendt K, Hurst J, Kitsos G, Niedrist D, et al: A report on 10 new patients with heterozygous mutations in the COL11A1 gene and a review of genotype-phenotype correlations in type XI collagenopathies. Am J Med Genet A 2007, 143(3):258-264
38. McAlinden A, Majava M, Bishop PN, Perveen R, Black GC, Pierpont ME, AlaKokko L, Mannikko M: Missense and nonsense mutations in the alternatively-spliced exon 2 of COL2A1 cause the ocular variant of Stickler syndrome. Hum Mutat 2008, 29(1):83-90.

39. Mikhak Z, Kelly P, Cohen TS, Cox JE, Kimonis VE: Immunoglobulin deficiency in Stickler syndrome. Am J Med Genet A 2006, 140(24):2824-2827.

40. Nagendran S, Richards AJ, McNinch A, Sandford RN, Snead MP: Somatic mosaicism and the phenotypic expression of COL2A1 mutations. Am J Med Genet A 2012, 158A(5):1204-1207.

41. Nikopoulos K, Schrauwen I, Simon M, Collin RW, Veckeneer M, Keymolen K, Van Camp G, Cremers FP, van den Born LI: Autosomal recessive Stickler syndrome in two families is caused by mutations in the COL9A1 gene. Invest Ophthalmol Vis Sci 2011, 52(7):4774-4779.

42. Nishimura G, Haga N, Kitoh H, Tanaka Y, Sonoda T, Kitamura M, Shirahama S, Itoh T, Nakashima E, Ohashi $\mathrm{H}$, et al: The phenotypic spectrum of COL2A1 mutations. Hum Mutat 2005, 26(1):36-43

43. Olavarrieta L, Morales-Angulo C, del Castillo I, Moreno F, Moreno-Pelayo MA Stickler and branchio-oto-renal syndromes in a patient with mutations in EYA1 and COL2A1 genes. Clin Genet 2008, 73(3):262-267.

44. Parma ES, Korkko J, Hagler WS, Ala-Kokko L: Radial perivascular retinal degeneration: a key to the clinical diagnosis of an ocular variant of Stickler syndrome with minimal or no systemic manifestations. Am J Ophthalmol 2002, 134(5):728-734

45. Poulson AV, Hooymans JM, Richards AJ, Bearcroft P, Murthy R, Baguley DM, Scott JD, Snead MP: Clinical features of type 2 Stickler syndrome. J Med Genet 2004, 41(8):e107.

46. Richards AJ, Baguley DM, Yates JR, Lane C, Nicol M, Harper PS, Scott JD, Snead MP: Variation in the vitreous phenotype of Stickler syndrome can be caused by different amino acid substitutions in the $X$ position of the type II collagen Gly-X-Y triple helix. Am J Hum Genet 2000, 67(5):1083-1094

47. Richards AJ, Laidlaw M, Whittaker J, Treacy B, Rai H, Bearcroft P, Baguley DM, Poulson A, Ang A, Scott JD, et al: High efficiency of mutation detection in type 1 stickler syndrome using a two-stage approach: vitreoretinal assessment coupled with exon sequencing for screening COL2A1. Hum Mutat 2006, 27(7):696-704

48. Richards AJ, Martin S, Yates JR, Scott JD, Baguley DM, Pope FM, Snead MP: COL2A1 exon 2 mutations: relevance to the Stickler and Wagner syndromes. Br J Ophthalmol 2000, 84(4):364-371.

49. Richards AJ, Meredith S, Poulson A, Bearcroft P, Crossland G, Baguley DM, Scott JD, Snead MP: A novel mutation of COL2A1 resulting in dominantly inherited rhegmatogenous retinal detachment. Invest Ophthalmol Vis Sci 2005, 46(2):663-668.

50. Ritvaniemi P, Hyland J, Ignatius J, Kivirikko Kl, Prockop DJ, Ala-Kokko L: A fourth example suggests that premature termination codons in the COL2A1 gene are a common cause of the Stickler syndrome: analysis of the COL2A1 gene by denaturing gradient gel electrophoresis. Genomics 1993, 17(1):218-221.

51. Sirko-Osadsa DA, Murray MA, Scott JA, Lavery MA, Warman ML, Robin NH: Stickler syndrome without eye involvement is caused by mutations in COL11A2, the gene encoding the alpha2(XI) chain of type XI collagen. J Pediatr 1998, 132(2):368-371.

52. Stevenson DA, Vanzo R, Damjanovich $\mathrm{K}$, Hanson $\mathrm{H}$, Muntz H, Hoffman RO, Bayrak-Toydemir P: Mosaicism in Stickler syndrome. Eur J Med Genet 2012, 55(6-7):418-422

53. van Beelen E, Leijendeckers JM, Huygen PL, Admiraal RJ, Hoefsloot $L H$, Lichtenbelt KD, Stobe L, Pennings RJ, Leuwer R, Snik AF, et al: Audiometric characteristics of two Dutch families with non-ocular Stickler syndrome (COL11A2). Hear Res 2012, 291(1-2):15-23.

54. Van Der Hout AH, Verlind E, Beemer FA, Buys CH, Hofstra RM, Scheffer $\mathrm{H}$ : Occurrence of deletion of a COL2A1 allele as the mutation in Stickler syndrome shows that a collagen type II dosage effect underlies this syndrome. Hum Mutat 2002, 20(3):236.

55. Vuoristo MM, Pappas JG, Jansen V, Ala-Kokko L: A stop codon mutation in COL11A2 induces exon skipping and leads to non-ocular Stickler syndrome. Am J Med Genet A 2004, 130A(2):160-164.

56. Yaguchi H, Ikeda T, Osada H, Yoshitake Y, Sasaki H, Yonekura H: Identification of the COL2A1 mutation in patients with type I Stickler 
syndrome using RNA from freshly isolated peripheral white blood cells. Genet Test Mol Biomarkers 2011, 15(4):231-237.

57. Zechi-Ceide RM, Jesus Oliveira NA, Guion-Almeida ML, Antunes LF, RichieriCosta A, Passos-Bueno MR: Clinical evaluation and COL2A1 gene analysis in 21 Brazilian families with Stickler syndrome: identification of novel mutations, further genotype/phenotype correlation, and its implications for the diagnosis. Eur J Med Genet 2008, 51(3):183-196.

58. Li K, Thorne C: Adult presentation of Stickler syndrome type III. Clin Rheumatol 2010, 29(7):795-797.

59. Martin S, Richards AJ, Yates JR, Scott JD, Pope M, Snead MP: Stickler syndrome: further mutations in COL11A1 and evidence for additional locus heterogeneity. Eur J Hum Genet 1999, 7(7):807-814

60. Wilkin DJ, Liberfarb R, Davis J, Levy HP, Cole WG, Francomano CA, Cohn DH: Rapid determination of COL2A1 mutations in individuals with Stickler syndrome: analysis of potential premature termination codons. Am J Med Genet 2000, 94(2):141-148.

61. Ang A, Ung T, Puvanachandra N, Wilson L, Howard F, Ryalls M, Richards A, Meredith S, Laidlaw M, Poulson A, et al: Vitreous phenotype: a key diagnostic sign in Stickler syndrome types 1 and 2 complicated by double heterozygosity. Am J Med Genet A 2007, 143(6):604-607.

62. Ritvaniemi P, Korkko J, Bonaventure J, Vikkula M, Hyland J, Paassilta P, Kaitila I, Kaariainen H, Sokolov BP, Hakala M, et al: Identification of COL2A1 gene mutations in patients with chondrodysplasias and familial osteoarthritis. Arthritis Rheum 1995, 38(7):999-1004.

63. Stickler GB, Hughes W, Houchin P: Clinical features of hereditary progressive arthro-ophthalmopathy (Stickler syndrome): a survey. Genet Med 2001, 3(3):192-196.

64. Khetarpal U, Robertson NG, Yoo TJ, Morton CC: Expression and localization of COL2A1 mRNA and type II collagen in human fetal cochlea. Hear Res 1994, 79(1-2):59-73.

65. Shpargel KB, Makishima T, Griffith AJ: Col11a1 and Col11a2 mRNA expression in the developing mouse cochlea: implications for the correlation of hearing loss phenotype with mutant type XI collagen genotype. Acta Otolaryngol 2004, 124(3):242-248.

66. McGuirt WT, Prasad SD, Griffith AJ, Kunst HPM, Green GE, Shpargel KB, Runge C, Huybrechts C, Mueller RF, Lynch E, et al: Mutations in COL11A2 cause non-syndromic hearing loss (DFNA13). Nat Genet 1999, 23(4):413-419.

67. De Leenheer EM, McGuirt WT, Kunst HP, Huygen PL, Smith RJ, Cremers CW: The phenotype of DFNA13/COL11A2. Adv Otorhinolaryngol 2002, 61:85-91

68. Chen W, Kahrizi K, Meyer NC, Riazalhosseini Y, Van Camp G, Najmabadi H, Smith RJH: Mutation of COL11A2 causes autosomal recessive non-syndromic hearing loss at the DFNB53 locus. J Med Genet 2005, 42(10):e61.

69. Melkoniemi M, Brunner HG, Manouvrier S, Hennekam R, Superti-Furga A, Kaariainen H, Pauli RM, van Essen T, Warman ML, Bonaventure J, et al: Autosomal recessive disorder otospondylomegaepiphyseal dysplasia is associated with loss-of-function mutations in the COL11A2 gene. Am J Hum Genet 2000, 66(2):368-377.

70. Masaki K, Gu JW, Ghaffari R, Chan G, Smith RJ, Freeman DM, Aranyosi AJ: Col11a2 deletion reveals the molecular basis for tectorial membrane mechanical anisotropy. Biophys J 2009, 96(11):4717-4724.

71. Asamura K, Abe S, Imamura Y, Aszodi A, Suzuki N, Hashimoto S, Takumi Y, Hayashi T, Fassler R, Nakamura Y, et al: Type IX collagen is crucial for normal hearing. Neuroscience 2005, 132(2):493-500.

72. Suzuki N, Asamura K, Kikuchi Y, Takumi Y, Abe S, Imamura Y, Hayashi T, Aszodi A, Fassler R, Usami S: Type IX collagen knock-out mouse shows progressive hearing loss. Neurosci Res 2005, 51(3):293-298.

73. Briggs MD, Chapman KL: Pseudoachondroplasia and multiple epiphyseal dysplasia: mutation review, molecular interactions, and genotype to phenotype correlations. Hum Mutat 2002, 19(5):465-478.

74. Snead MP, McNinch AM, Poulson AV, Bearcroft P, Silverman B, Gomersall P, Parfect V, Richards AJ: Stickler syndrome, ocular-only variants and a key diagnostic role for the ophthalmologist. Eye (Lond) 2011, 25(11):1389-1400.

75. Yoo TJ, Tomoda K: Type II collagen distribution in rodents. Laryngoscope 1988, 98(11):1255-1260.

76. Knutsson J, Bagger-Sjoback D, von Unge M: Collagen type distribution in the healthy human tympanic membrane. Otol Neurotol 2009, 30(8): 1225-1229.
77. Vanniasegaram I, Bellman S: Vestibular function in Stickler's syndrome. J Audiological Med 1994, 3:129-150.

78. Rai A, Wordsworth P, Coppock JS, Zaphiropoulos GC, Struthers GR: Hereditary arthro-ophthalmopathy (Stickler syndrome): a diagnosis to consider in familial premature osteoarthritis. Br I Rheumatol 1994, 33(12):1175-1180.

79. Nowak CB: Genetics and hearing loss: a review of Stickler syndrome. J Commun Disord 1998, 31(5):437-453. 453-434.

doi:10.1186/1750-1172-7-84

Cite this article as: Acke et al:: Hearing impairment in Stickler syndrome: a systematic review. Orphanet Journal of Rare Diseases 2012 7:84.

\section{Submit your next manuscript to BioMed Central and take full advantage of:}

- Convenient online submission

- Thorough peer review

- No space constraints or color figure charges

- Immediate publication on acceptance

- Inclusion in PubMed, CAS, Scopus and Google Scholar

- Research which is freely available for redistribution 